\title{
Evolution of the Surface Area of Limestone during Calcination and Sintering
}

\author{
Yang Liu, Yongping Yang \\ School of Energy Power and Mechanical Engineering, North China Electric Power University, Beijing, China \\ Email: hdliuyang@163.com
}

Received December 2014

\begin{abstract}
The calcination reaction of limestone is always companied by sintering of the calcined product. In addition, accelerated sintering rates and a reduced specific surface area are observed in the presence of steam and carbon dioxide. To simulate the change of surface area and the porosity of limestone samples in a simultaneous calcination and sintering process, a combined model based on both a sintering model and a calcination model is established. The calcination model, which predicts calcination conversion as a function of time, is based on the initial properties of the sorbent. The sintering model is according to the German and Munir model in which the main transport mechanism is supposed to be lattice diffusion. In a flow reactor, the surface area value and calcination rate of limestone in the presence of steam and $\mathrm{CO}_{2}$ are also described by the combined model with modified parameters.
\end{abstract}

\section{Keywords}

\section{Calcination, Sintering, Limestone, Combined Model}

\section{Introduction}

Sintering refers to the changes in pore shape, pore shrinkage and the increase in grain size that $\mathrm{CaO}$ particles undergo during heating. The rate of $\mathrm{CaO}$ sintering increases at higher temperatures, as well as at higher partial pressures of carbon dioxide and steam vapor. The presence of impurities also increases the sintering rate. In general, higher temperatures are required to increase reaction rates, but because of the sintering process, the structure of the calcine is more likely to change.

Beruto et al. [1] found that the surface area of $\mathrm{CaO}$ produced from calcite crystals is constant at $116 \mathrm{~m}^{2} / \mathrm{g}$ when the calcite crystals are decomposed under vacuum at $686^{\circ} \mathrm{C}$. The volume occupied by a $\mathrm{CaO}$ aggregate is $98 \%$ that of the original calcite crystal. Powell and Searcy [2] also obtained the same surface area value for $\mathrm{CaO}$ in another apparatus with good evacuation. Furthermore, Beruto et al. [3] noticed the influence of $\mathrm{CO}_{2}$ pressure on sintering when they measured a surface area of $89 \mathrm{~m}^{2} / \mathrm{g} \mathrm{CaO}$ from the decomposition of large crystals of calcite at $580^{\circ} \mathrm{C}$ when the evacuation was less complete because of low vacuum pump speed.

Large particles of limestone calcinated in a rotary kiln at $980^{\circ} \mathrm{C}$ normally resulted in surface areas of only 2 to $5 \mathrm{~m}^{2} / \mathrm{g}$. Chan et al. [4] attained a surface area of $24.6 \mathrm{~m}^{2} / \mathrm{g}$ by calcining limestone particles in a TGA at $745^{\circ} \mathrm{C}$. 
Fennell et al. [5] obtained the largest surface area of $39 \mathrm{~m}^{2} / \mathrm{g}$ at $1023 \mathrm{~K}$ in the study of the effect of repeated cycles on sorbent activity. Sun et al. [6] also found a surface area of $36 \mathrm{~m}^{2} / \mathrm{g}$ using Strassburg limestone in a TGA at $850^{\circ} \mathrm{C}$. The TGA generally employed for these studies is limited to samples with a relative large particle density due to poor dispersion in the sample holder. The low gas throughput of the sample imposes another severe limitation because it aggravates the effect of $\mathrm{CO}_{2}$ on sintering.

There exists evidence that the sintering mechanism of $\mathrm{CaO}$ is fundamentally related to the mass transport. Borgwardt et al. [7] noticed that the product layer diffusivities for the sulfation of $\mathrm{CaO}$ of varying purity show higher values when the $\mathrm{CaO}$ is derived from limestones than when it comes from pure $\mathrm{CaCO}_{3}$. Further more, the addition of small amounts of certain salts is found to enhance sulfation especially when added to presintered $\mathrm{CaO}$. The ions in these salts, such as $\mathrm{Li}^{+}, \mathrm{Na}^{+}, \mathrm{Cr}^{3+}$ and $\mathrm{Mo}^{3+}$, when incorporated into a $\mathrm{CaO}$ lattice, produce defects that promote solid state diffusion. Similar effects of these foreign ions are observed on the sintering of $\mathrm{CaO}$. By comparing the result of the $\mathrm{CO}_{2}$ looping cycle performance of a limestone, Manovic et al. [8] believed that the presence of $\mathrm{Na}$ ions increases the diffusion of $\mathrm{Ca}$ ions and that this enhanced diffusion accelerates the gassolid reaction. From SEM images, Manovic et al. also observed the pronounced sintering and the loss of surface area as a result of the presence of $\mathrm{Na}$ ions in the $\mathrm{CaO}$ powder. As a result, Borgwardt et al. [9] found that the activation energy for the sintering of pure $\mathrm{CaO}$ is greater than that for the impure material. Therefore, the observed effects are consistent with the hypothesis that diffusion through the product layer occurs by ionic transport and that the mechanism of sintering is related to the mechanism of product layer diffusion.

This paper describes a combined model, based on a sintering model from German and Munir [10] and a first-order calcination model from Borgwardt [11]. Supposing that the surface area of limestone varies linearly with the mole fraction of $\mathrm{CaO}$ in the sample in the absence of sintering, the simulation results during simultaneous calcination and sintering are shown at various reaction temperatures. In the presence of steam and $\mathrm{CO}_{2}$, the German-Munir model is also used to simulate an isothermal sintering process. The combined model is beneficial to the understanding of the diffusion mechanism in calcination and sintering reaction with or without a catalyzed atmosphere.

\section{Model Description}

\subsection{Calcination and Sintering Model}

Beruto and Searcy [12] showed that the calcination rate per unit area of a flat crystal surface is constant at a given temperature and calcination rates for limestone have been presented as a first-order Arrhenius expression, thus

$$
\frac{\mathrm{d} w_{\mathrm{CaCO}_{3}}}{\mathrm{~d} t}=-K_{\mathrm{c}} A_{\mathrm{CaCO}_{3}}
$$

where $w_{\mathrm{CaCO}}$ is the mass of the undecomposed calcium carbonate, $K_{\mathrm{c}}$ is the rate constant of the calcination reaction, and $A_{\mathrm{CaCO}}$ is the surface area of the calcium carbonate. Assuming that the induction period of the calcination can be neglected [13], the calcination rate at time $t$ is proportional to the BET surface area of the undecomposed $\mathrm{CaCO}_{3}$, thus

$$
A_{\mathrm{CaCO}_{3}}=s_{g} w_{\mathrm{CaCO}_{3}}
$$

where $s_{\mathrm{g}}$ is the specific BET surface area of limestone per unit mass. The rate expression given by Equation (1) can be integrated as:

$$
\int_{1}^{1-x} \frac{\mathrm{d} w_{\mathrm{CaCO}_{3}}}{w_{\mathrm{CaCO}_{3}}}=-K_{c} s_{g} \int_{0}^{t} \mathrm{~d} t
$$

This yields the following calcination model for small particles:

$$
\ln (1-x)=-K_{c} s_{g} t
$$

where $x$ is fractional conversion of $\mathrm{CaCO}_{3}$ to $\mathrm{CaO}$. The rate constant for the surface reaction in the Borgwardt [13] model showed an independent trend with the type of stone and the particle size from 1 to $90 \mu \mathrm{m}$. The equation accurately fits the measured extent of calcination as a function of time. Thus, the model of Borgwardt is utilized in the following calculation. 
German and Munir [10] proposed a model of the interparticle neck shape during sintering. The following generalized expression is derived for this process:

$$
\left(\frac{S_{0}-S}{S_{0}}\right)^{\gamma}=K_{s} t
$$

where $S_{0}$ is the initial specific surface area, $S$ is the specific surface at time $t$, and $K_{s}$ is the sintering rate constant. The exponent $\gamma$ has unique values for the different transport mechanisms. Using the German-Munir model, Borgwardt [9] compared the rate of the surface area reduction in $\mathrm{CaO}$ that was derived from limestone. The exponent $\gamma$ in Equation (5) was estimated by fitting the widest range of $\Delta S$ values. Values of $\gamma=2.7$ yielded the best fit with these data. Thus, the model of Borgwardt is utilized in the following calculation.

Assuming that the $\mathrm{CO}_{2}$ effect and the sintering of the calcine can be omitted under the differential condition, the surface area during calcination can be expressed as:

$$
S_{i d}=S_{k} x+S_{i}
$$

where $S_{i d}$ is the surface area supposing that no sintering happens, $S_{k}$ is the surface area constant and $S_{i}$ is the initial surface area of the limestone.

According to this model, the $\mathrm{CaO}$ product is divided into increments depending on the time interval in which each increment is formed. At the $j$ th time interval, the $\mathrm{CaO}$ produced in the ith time interval experienced the sintering time of the $j$-ith interval. Equation (5) can thus be rewritten as:

$$
S=S_{i d}\left(1-\left(K_{s}\left(t_{j}-t_{i}\right)\right)^{1 / \gamma}\right)
$$

where $S_{\text {id }}$ is the initial specific surface area and can be determined according to Equation (6). The surface area of the $\mathrm{CaO}$ formed during the ith time interval can be calculated by Equation (7) at the end of the $j$ th time interval. The surface area of the entire product and the overall specific surface area of the calcined particle are calculated as

$$
\begin{gathered}
S_{\text {СаO }}=\sum_{i=1}^{i=j} S_{i, j} z_{i} \\
S_{S}(x, t)=x S_{\text {СаO }}+(1-x) S_{\mathrm{CaCO}_{3}}
\end{gathered}
$$

where $S_{i, j}$ is the specific surface area of the $\mathrm{CaO}$ formed in the ith time interval at the end of the $j$ th time interval, $z_{i}$ is the fraction of the total $\mathrm{CaO}$ formed in the ith time interval, $S_{\mathrm{CaO}}$ is the specific surface area of the $\mathrm{CaO}$ product and $S_{\mathrm{CacO}}$ is the specific surface area of the $\mathrm{CaCO}_{3}$.

In a review of much previous research, Milne et al. [14] compared the surface area and porosity measurements for carbonate-derived $\mathrm{CaO}$ with differing degrees of sintering and varying calcination conditions and found that when the surface area $S$ is plotted against the porosity, a linear regression of many of the data sets passes through the origin. The upper limit of the data is represented by a curve. The empirical formula is utilized in this combined model and the specific surface area along this curve is expressed as:

$$
S=84.94 \frac{\varepsilon}{1-\varepsilon}
$$

Equation (4) is utilized to evaluate the conversion change with time. With Equations (6)-(9), the value of $S$ is determined. The resultant porosity is determined with Equation (10).

\subsection{Sintering Model in the Presence of Steam and $\mathrm{CO}_{2}$}

The sintering process that occurs in $\mathrm{N}_{2}$ can be described with two parameters of $K_{s}$ and $\gamma$, one temperature dependent and the other mechanism dependent. In true flue gas, both steam and $\mathrm{CO}_{2}$ accelerate the $\mathrm{CaO}$ sintering. Anderson et al. [15] found that the surface reduction of $\mathrm{CaO}$ is sensitive to water vapor and that the reduction is due to crystallite growth, not merely agglomeration and closure of pores. Beruto et al. [16] showed the catalytic effect of $\mathrm{CO}_{2}$ by measurements of the surface area and porosity reduction in $\mathrm{CaO}$ below the equilibrium pressure of $\mathrm{CaCO}_{3}$ decomposition. In the presence of steam and $\mathrm{CO}_{2}$, sintering is a process involving multiple transport 
mechanisms, so Equation (5) can not be strictly applied. The rate constant $K$ and $\gamma$ both change with gas composition and temperature as more than one mechanism becomes effective. Because this is an empirical approach, the values of $K$ and $\gamma$ no longer have significance regarding the sintering mechanism.

The experiment results of Borgwardt [17] show that the parameter $\gamma$ becomes dependent on temperature and partial pressure in the presence of steam and $\mathrm{CO}_{2}$.

The relationships between $\gamma$ and the partial pressure of steam or $\mathrm{CO}_{2}$ can separately be expressed as

$$
\begin{aligned}
& \ln \gamma_{\mathrm{H}_{2} \mathrm{O}}=0.00262 T+\left(\ln P_{\mathrm{H}_{2} \mathrm{O}}-1.39\right) / 11.1 \\
& \ln \gamma_{\mathrm{CO}_{2}}=0.0034 T+\left(\ln P_{\mathrm{CO}_{2}}-1.948\right) / 44.9
\end{aligned}
$$

The parameter $\gamma$ in presence of steam and $\mathrm{CO}_{2}$ is a function of temperature and the composition of the sintering atmosphere and can be expressed as

$$
\gamma_{\mathrm{H}_{2} \mathrm{O}+\mathrm{CO}_{2}}=0.376\left(\gamma_{\mathrm{H}_{2} \mathrm{O}}+\gamma_{\mathrm{CO}_{2}}\right)+8.8
$$

The parameter $K_{s}$ in atmospheres containing both steam and $\mathrm{CO}_{2}$ is given by

$$
\ln K_{s}=1.485+0.558 \ln P_{\mathrm{CO}_{2}}-11660 / T
$$

Combining Equations (11)-(14) with Equation (5), an empirical model for $S$ as a function of time is given.

\section{Simulated Results of Models}

Although there are a large number of calcine-sintering experiments, work on the simultaneous calcination and sintering process under the differential condition is scarce. In this paper, the rate constant $K_{c}$ for the surface reaction in the calcination model is first determined by the experimental data from the flow reactor with $10 \mu \mathrm{m}$ Fredonia limestone [13]. Second, the sintering rate constant $K_{s}$ in the sintering model is acquired using the surface-area reduction curve in a particle size range of 2 to $20 \mu \mathrm{m}$ using the same Fredonia limestone [9] because the effect of particle size on the sintering rate in this range can be omitted. The BET surface area of $10 \mu \mathrm{m}$ Fredonia limestone is $0.86 \mathrm{~m}^{2} / \mathrm{g}$. The calcination and sintering activation energies are calculated separately by the rate constant point at the temperature range indicated. It should be noted that the surface area constant $\left(S_{k}\right)$ must be determined accurately and uncertainties in $S_{k}$ will significantly influence the surface area calculated. Because sintering occurs even at low temperatures during the calcination process, the value can not be obtained by BET measurement. Fredonia limestone with a particle diameter of $10 \mu \mathrm{m}$ were calcined in the differential reactor at $700^{\circ} \mathrm{C}$ and a mean value of $104 \mathrm{~m}^{2} / \mathrm{g}$ was used for all calculations involving the $\mathrm{CaCO}_{3}$ derivative [9]. Thus, the surface area constant calculated by the combined model at $700^{\circ} \mathrm{C}$ is $107 \mathrm{~m}^{2} / \mathrm{g}$ and this surface area constant is utilized in the combined model at various calcination temperatures. Supposing that the calcination reaction of Fredonia limestone is performed at $700^{\circ} \mathrm{C}-1000^{\circ} \mathrm{C}$, the predictions of the model at various reaction temperatures with a particle diameter of $10 \mu \mathrm{m}$ is shown in Figure $\mathbf{1}$ and the combined model parameters and the simulated results are listed in Table $\mathbf{1 .}$

According to the calculation results of the combined model, the uppermost value of $104.2 \mathrm{~m}^{2} / \mathrm{g}$ happened at 114.7 second for Fredonia limestone calcinated at $700^{\circ} \mathrm{C}$. Even one minute later, the value of the surface area heated at $700^{\circ} \mathrm{C}$ is more than $104 \mathrm{~m}^{2} / \mathrm{g}$. The change in surface area after the calcination reaction is not significant, which is the reason that Borgwardt prepared the precalcined limestone sample at $700^{\circ} \mathrm{C}$. When the calcination temperature is increased from $700^{\circ} \mathrm{C}$ to $1000^{\circ} \mathrm{C}$, the period of complete calcination is reduced from 114.7 sec to 0.4 sec, which is shown in Table 1. However, the maximum surface area under various calcination temperatures does not change much before the temperature effect on sintering becomes significant in the ensuing period. Figure 1 also shows that increasing the reaction temperature enhances the calcination rate and the sintering rate, which causes the surface area and the porosity of a limestone sample calcined at $1000^{\circ} \mathrm{C}$ to decrease to values of $78 \mathrm{~m}^{2} / \mathrm{g}$ and 0.45 , respectively, after a $60 \mathrm{sec}$ reaction time.

In Figure 2, the calcination rate and surface area data reported by Bortz et al. [18] of $13 \mu \mathrm{m}$ Marianna limestone calcined in a flow reactor at $1373 \mathrm{~K}$ are compared with the prediction of the model in the presence of steam and $\mathrm{CO}_{2}$. Because the initial surface area of Marianna limestone is not provided in the work of Bortz, the BET surface area of $0.86 \mathrm{~m}^{2} / \mathrm{g}$ is assumed in this model. The parameter of $K_{c}$ is obtained from the calcination rate in Figure 2(a). The partial pressures of $\mathrm{CO}_{2}$ and steam in the flue gas atmosphere are $7.5 \mathrm{kPa}$ and $14 \mathrm{kPa}$, respec- 

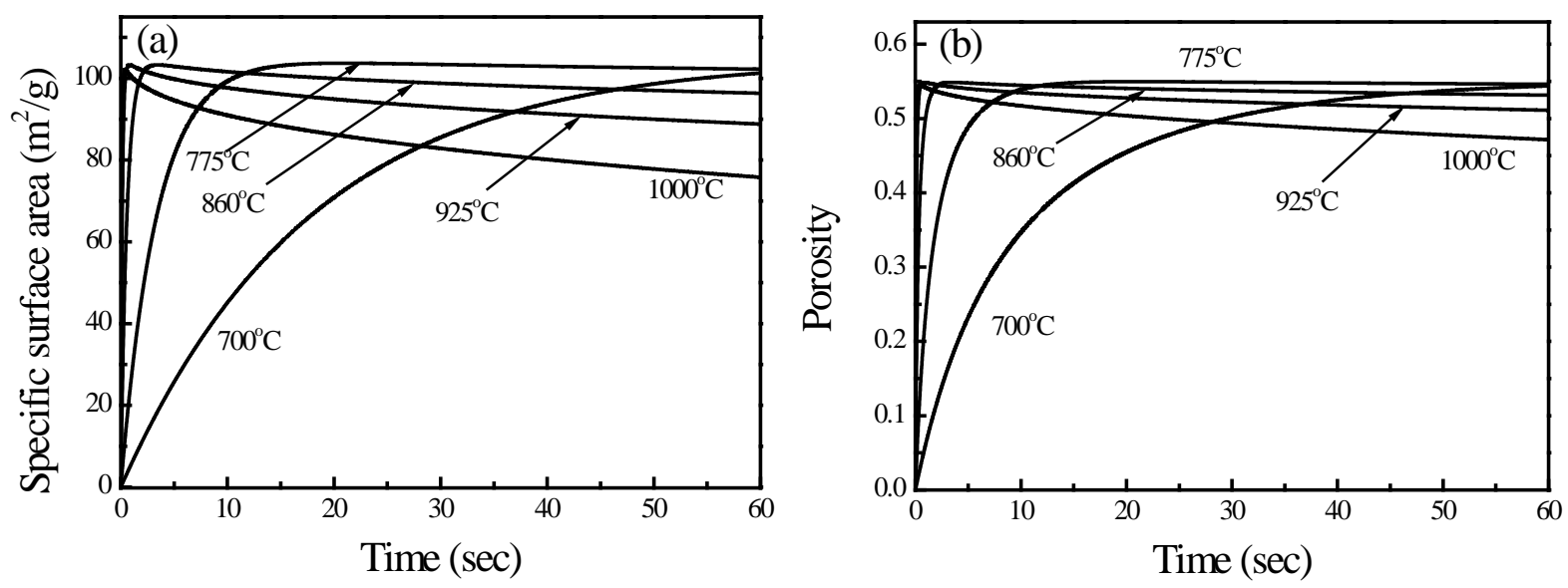

Figure 1. The effect of simultaneous calcination and sintering under various reaction temperatures on (a) specific surface area, and (b) porosity.
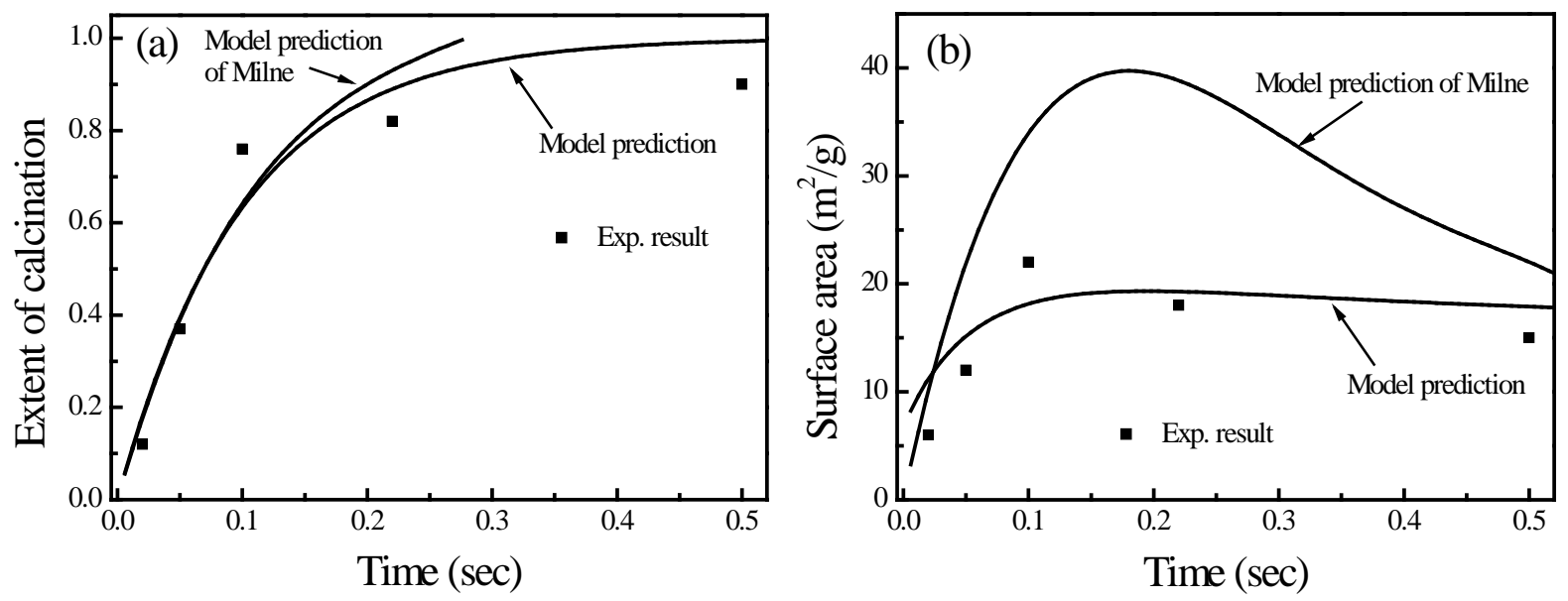

Figure 2. Model prediction for $13 \mu \mathrm{m}$ Marianna limestone calcined at $1373 \mathrm{~K}$ in a flow reactor [18], (a) Extent of calcination, and (b) Surface area.

Table 1. Model parameters and simulated results.

\begin{tabular}{ccccc}
\hline $\mathrm{T}\left({ }^{\circ} \mathrm{C}\right)$ & $K_{c}\left(\mathrm{~g} / \mathrm{m}^{2} \cdot \mathrm{min}\right)$ & $K_{s}(1 / \mathrm{t})$ & $S_{\text {Max }}\left(\mathrm{m}^{2} / \mathrm{g}\right)$ & $t(\mathrm{Sec})$ \\
\hline 700 & 3.8 & 0.000027 & 104.2 & 114.7 \\
775 & 20.5 & 0.00024 & 103.7 & 20.8 \\
860 & 120.5 & 0.002 & 103.3 & 3.5 \\
925 & 500.5 & 0.0084 & 103.3 & 0.8 \\
1000 & 1000.5 & 0.036 & 102.2 & 0.4 \\
\hline
\end{tabular}

tively. The parameters $\gamma$ and $K_{s}$, calculated with Equation (13) and Equation (14), are 45 and 0.02 , respectively. Figure 2(b) shows a comparison between the predictions of the Milne model [14] and that of the model in this paper. Milne applied an empirical surface area expression to reflect the influence of steam and $\mathrm{CO}_{2}$ and a prior knowledge of the asymptotic surface area as a function of temperature should be required. The sintering model of this paper in the presence of steam and $\mathrm{CO}_{2}$ utilizes only the German-Munir model and the parameters of $\gamma$ and $K_{s}$ are obtained only according to the simulation formula provide by Borgwardt [17]. The model prediction is closer to the actual surface area of the $13 \mu \mathrm{m}$ Marianna limestone. The experimental result and model simulation show that the surface area reduction is accelerated in the presence of steam and $\mathrm{CO}_{2}$. The sintering activation energy in the presence of steam and $\mathrm{CO}_{2}$ is $97 \mathrm{~kJ} / \mathrm{mol}$, calculated with the diffusion coefficient $K_{s}$, 
which is much less than the sintering activation energy in $\mathrm{N}_{2}$. The increased sintering rate caused by steam and $\mathrm{CO}_{2}$ is in accord with the expected effect of surface diffusion and grain boundary diffusion. Relative to the sintering rate of lattice diffusion, these two diffusions reduce the apparent sintering activation energy and increase the diffusivity. According to the combined model, at $1100^{\circ} \mathrm{C}$ the surface area of Fredonia limestone produces the maximum observed value of $102.2 \mathrm{~m}^{2} / \mathrm{g}$ at $0.08 \mathrm{sec}$ in $\mathrm{N}_{2}$. However, the result of the model in the presence of steam and $\mathrm{CO}_{2}$ suggests an approximate peak surface area of $18.5 \mathrm{~m}^{2} / \mathrm{g}$ at $0.15 \mathrm{sec}$, which is shown in Figure 2(b). A shift of the primary sintering mechanism from slow lattice diffusion to the faster mechanism would agree with the effects apparent from this comparison.

\section{Conclusion}

The German-Munir model not only can be used to correlate the kinetics of the $\mathrm{CaO}$ surface area reduction in inert atmospheres but also can be modified to empirically account for the effects of steam and $\mathrm{CO}_{2}$. The surface area value and porosity of limestone samples in simultaneous calcination and sintering process is determined by a combined model. The surface area reduction during sintering suggests that besides lattice diffusion both surface diffusion and grain boundary mechanisms are more evident in the presence of steam and $\mathrm{CO}_{2}$.

\section{Acknowledgements}

This research was supported by the National Natural Science Foundation of China (No. 51025624), the 111 project (B12034) and the Fundamental Research Funds for the Central Universities (2014QN08). The author is grateful for the supporting of Australia-China JCG Round 2 Partnership Funding.

\section{References}

[1] Beruto, D., Barco, L. and Searcy, A.W. (1983) Rearrangement of Porous CaO Aggregates during Calcite Decomposition in Vacuum. Journal of the American Ceramic Society, 66, 893-896. http://dx.doi.org/10.1111/j.1151-2916.1983.tb11008.x

[2] Powell, E.K. and Searcy, A.W. (1982) Surface Areas and Morphologies of CaO Produced by Decomposition of Large $\mathrm{CaCO}_{3}$ Crystals in Vacuum. Journal of the American Ceramic Society, 65, C42-C44. http://dx.doi.org/10.1111/j.1151-2916.1982.tb10395.x

[3] Beruto, D., Barco, L., et al. (1980) Characterization of the Porous CaO Particles Formed by Decomposition of $\mathrm{CaCO}_{3}$ and $\mathrm{Ca}(\mathrm{OH})_{2}$ in Vacuum. Journal of the American Ceramic Society, 63, 439-443. http://dx.doi.org/10.1111/j.1151-2916.1980.tb10208.x

[4] Chan, R.K., Murthi, K.S. and Harrison, D. (1970) Thermogravimetric Analysis of Ontario Limestone and Dolomites. 1. Calcination, Surface Area and Porosity. Canadian Journal of Chemistry, 48, 2972-2978. http://dx.doi.org/10.1139/v70-503

[5] Fennell, P.S., Pacciani, R., et al. (2007) The Effects of Repeated Cycles of Calcination and Carbonation on a Variety of Different Limestones, as Measured in a Hot Fluidized Bed of Sand. Energy Fuels, 21, 2072-2081. http://dx.doi.org/10.1021/ef060506o

[6] Sun, P., Grace, J.R., et al. (2007) The Effect of CaO Sintering on Cyclic $\mathrm{CO}_{2}$ Capture in Energy Systems. AIChE Journal, 53, 2432-2442. http://dx.doi.org/10.1002/aic.11251

[7] Borgwardt, R.H., Bruce, K.R., et al. (1987) An Investigation of Product-Layer Diffusivity for CaO Sulfation. Industrial \& Engineering Chemistry Research, 26, 1993-1998. http://dx.doi.org/10.1021/ie00070a010

[8] Manovic, V., Anthony, E.J., et al. (2008) $\mathrm{CO}_{2}$ Looping Cycle Performance of a High-Purity Limestone after Thermal Activation/Doping. Energy Fuels, 22, 3258-3264. http://dx.doi.org/10.1021/ef800316h

[9] Borgwardt, R.H. (1989) Sintering of Nascent Calcium-Oxide. Chemical Engineering Science, 44, 53-60. http://dx.doi.org/10.1016/0009-2509(89)85232-7

[10] German, R.M. and Munir, Z.A. (1976) Surface-Area Reduction during Isothermal Sintering. Journal of the American Ceramic Society, 59, 379-383. http://dx.doi.org/10.1111/j.1151-2916.1976.tb09500.x

[11] Borgwardt, R.H. and Bruce, K.R. (1986) Effect of Specific Surface Area on the Reactivity of CaO with $\mathrm{SO}_{2}$. AIChE Journal, 32, 239-246. http://dx.doi.org/10.1002/aic.690320210

[12] Beruto, D. and Searcy, A.W. (1974) Use of the Langmuir Method for Kinetic Studies of Decomposition Reactions: Calcite $\left(\mathrm{CaCO}_{3}\right)$. Journal of the Chemical Society, Faraday Transactions 1: Physical Chemistry in Condensed Phases, 70, 2145-2153. http://dx.doi.org/10.1039/f19747002145 
[13] Borgwardt, R.H. (1985) Calcination Kinetics and Surface-Area of Dispersed Limestone Particles. AIChE Journal, 31, 103-111. http://dx.doi.org/10.1002/aic.690310112

[14] Milne, C.R., Silcox, G.D., et al. (1990) Calcination and Sintering Models for Application to High-Temperature, ShortTime Sulfation of Calcium-Based Sorbents. Industrial \& Engineering Chemistry Research, 29, 139-149. http://dx.doi.org/10.1021/ie00098a001

[15] Anderson, P.J., Horlock, R.F., et al. (1965) Some Effects of Water Vapour during the Preparation and Calcination of Oxide Powders. Proc. Br. Ceram. Soc, 3, 33.

[16] Beruto, D., Barco, L., et al. (1984) $\mathrm{CO}_{2}$-Catalyzed Surface-Area and Porosity Changes in High-Surface-Area CaO Aggregates. Journal of the American Ceramic Society, 67, 512-515. http://dx.doi.org/10.1111/j.1151-2916.1984.tb19644.x

[17] Borgwardt, R.H. (1989) Calcium-Oxide Sintering in Atmospheres Containing Water and Carbon-Dioxide. Industrial \& Engineering Chemistry Research, 28, 493-500. http://dx.doi.org/10.1021/ie00088a019

[18] Bortz, S.T., Roman, V.P., et al. (1986) Precalcination and Its Effect on Sorbent Utilization during Upper Furnace Injection.

\section{Notation}

\begin{tabular}{cl}
$A_{\mathrm{CaCO}}$ & Surface area of calcium carbonate, $\mathrm{m}^{2}$ \\
$K_{c}$ & Rate constant for surface area, $\mathrm{g} / \mathrm{m}^{2} \cdot \mathrm{min}$ \\
$K_{s}$ & Sintering rate constant in an inert atmosphere, $t^{-1}$ \\
$S$ & Specific surface area at time $t, \mathrm{~m}^{2} / \mathrm{g}$ \\
$S_{0}$ & Initial specific surface area of $\mathrm{CaO}$ following decomposition of its precursor, $\mathrm{m}^{2} / \mathrm{g}$ \\
$S_{\mathrm{CaO}}$ & Specific surface area of $\mathrm{CaO}$ product, $\mathrm{m}^{2} / \mathrm{g}$ \\
$S_{\mathrm{CaCO3}}$ & Specific surface area of $\mathrm{CaCO}_{3}, \mathrm{~m}^{2} / \mathrm{g}$ \\
$S_{k}$ & Surface area constant without the $\mathrm{CO}_{2}$ effect on sintering, $\mathrm{m}^{2} / \mathrm{g}$ \\
$S_{i}$ & Initial surface area of limestone, $\mathrm{m}^{2} / \mathrm{g}$ \\
$S_{i d}$ & Surface area supposing that no sintering happens, $\mathrm{m}^{2} / \mathrm{g}$ \\
$S_{i, j}$ & Specific surface area of CaO formed in the $i$ th time interval at the end of the $j$ th time interval, $\mathrm{m}^{2} / \mathrm{g}$ \\
$S_{s}$ & Overall specific surface area of the particle, $\mathrm{m}^{2} / \mathrm{g}$ \\
$S_{g}$ & Specific BET surface area of limestone, $\mathrm{m}^{2} / \mathrm{g}$ \\
$t$ & Time \\
$t_{i}$ & ith time interval \\
$t_{j}$ & ith time interval \\
$w_{\text {CaCO3 }}$ & Undecomposed calcium carbonate in sample, g \\
$x$ & Fractional conversion of CaCO ${ }_{3}$ to CaO \\
$z_{i}$ & Fraction of total CaO formed in the $i$ th time interval \\
\hline
\end{tabular}

\section{Greek letters}

\begin{tabular}{cl}
$\gamma$ & Mechanism-dependent exponent \\
$\gamma \mathrm{CO}_{2}$ & Mechanism-dependent exponent in atmosphere of $\mathrm{N}_{2}$ containing $\mathrm{CO}_{2}$ \\
$\gamma \mathrm{H}_{2} \mathrm{O}$ & Mechanism-dependent exponent in atmosphere of $\mathrm{N}_{2}$ containing $\mathrm{H}_{2} \mathrm{O}$ \\
$\gamma \mathrm{H}_{2} \mathrm{O}+\mathrm{CO}_{2}$ & Mechanism-dependent exponent in atmosphere of $\mathrm{N}_{2}$ containing $\mathrm{H}_{2} \mathrm{O}$ and $\mathrm{CO}_{2}$ \\
$\varepsilon$ & Porosity of sample \\
\hline
\end{tabular}

